\title{
VIAGEM NOSSA DE CADA DIA: o direito à educação superior e os desafios de permanência
}

\author{
JOURNEY OUR EVERY DAY: the right to higher education and \\ permanence challenges
}

Luciene Araujo ${ }^{1}$

\section{Resumo}

Nas últimas décadas, a democratização das universidades brasileiras tornouse temática central dos estudos relacionados à educação superior no Brasil. Destarte, o presente artigo buscou evidenciar as condições de acesso e permanência no ensino superior a partir do estudo da realidade de estudantes naturais da cidade de Russas-CE que ingressam nas universidades de Mossoró-RN. Utilizou-se da análise de questionários e entrevistas semiestruturadas com o propósito de depreender os elementos motivadores que levam esta juventude a se locomover diariamente para o estado potiguar, bem como as principais dificuldades que perpassam esta realidade. Adotamos a teoria crítica para apreender estes sujeitos na conjuntura a qual estão imersos e para nortear nossa revisão de literatura, possibilitando uma visão de totalidade e a compreensão dos determinantes do sistema capitalista nas iniciativas estatais. Desta feita, a pesquisa de campo nos possibilitou o entendimento das principais dificuldades que perpassam esta realidade, quais sejam: a distância entre os municipios, a sobrecarga do tempo, a condição financeira e o cansaço físico e mental. Por fim, afirmamos que as políticas de acesso e permanência devem buscar a garantia integral do direito à educação visando a efetiva democratização da universidade brasileira.

Palavras-chave: Democratização. Educação Superior. Assistência Estudantil.

\section{Abstract}

In the last decades, the democratization of Brazilian universities has become the central theme of studies related to higher education in Brazil. Thus, the present article sought to highlight the conditions of access and permanence in higher education based on the study of the reality of natural students of the city of Russas-CE who enter the universities of Mossoró-RN. It was used the analysis of questionnaires and semi-structured interviews with the purpose of

\footnotetext{
${ }^{1}$ Bolsista CAPES no Mestrado do Programa de Pós-graduação em Serviço Social e Direitos Sociais na Universidade do Estado do Rio Grande do Norte (UERN) (2018). Bacharela em Serviço Social pela UERN (2017). É membro do Grupo de Estudos e Pesquisas em Politicas Públicas (GEPP/UERN) desde 2017.
}

Interfaces da Educ., Paranaíba, v.10, n.28, p. 189 à 213, 2019 ISSN 2177-7691

Recebido em Dezembro de 2018/ Aprovado em Maio de 2019 
understanding the motivating elements that lead these youth to move daily to the state of Potiguar, as well as the main difficulties that permeate this reality. We adopt the critical theory to apprehend these subjects in the conjuncture to which they are immersed and to guide our literature review, allowing a vision of totality and the understanding of the determinants of the capitalist system in the state initiatives. This time, the field research enabled us to understand the main difficulties that permeate this reality, such as: distance between municipalities, time overload, financial condition and physical and mental fatigue. Finally, we affirm that the policies of access and permanence must seek the integral guarantee of the right to education aiming at the effective democratization of the Brazilian university.

Keywords: Democratization. Higher Education. Student Assistance.

\section{Considerações iniciais}

A educação superior é parte integrante do direito à educação, se propõe a preparar para o mundo do trabalho, propícia a autorrealização dos sujeitos, possibilita a aquisição de competências, habilidades e o aperfeiçoamento do intelecto (DRUMMOND, 2012). Contudo, a garantia deste direito é dicotomizada, uma vez que é considerado, primordialmente, como etapa necessária para a qualificação e venda da força de trabalho, responsável pela ascensão social dos sujeitos.

Atualmente, a formação profissional de nível superior, ofertada pelo Estado neoliberal brasileiro, enfrenta uma reconfiguração do seu ensino, bem como das formas de ingresso e permanência nas Instituições de Ensino Superior (IES's). Isto leva muitos a considerarem uma crescente democratização do acesso ao meio acadêmico, todavia as políticas voltadas para o financiamento da esfera privada descaracterizam o direito estabelecido pela Carta Magna de 1988 que dispõe sobre a sua gratuidade, universalidade e qualidade (BRASIL, 2013).

Destarte, no interim da lógica capitalista, a juventude de cidades de parco desenvolvimento econômico é forçada a buscar oportunidades de formação profissional de nível superior em municipios economicamente mais desenvolvidos. Posto isto, com o intuito de problematizar as condições de acesso nas IES's brasileiras e os desafios enfrentados para permanecer na academia, buscou-se evidenciar a realidade daquelas(es) estudantes que são 
impulsionadas(os) a saírem de sua cidade para obter um diploma em outro estado.

Fundamentando-se na teoria crítica - com o propósito de compreender as relações de produção e reprodução do capital nas atuais politicas de educação superior - investigamos as condições de acesso e permanência da juventude de Russas-CE que ingressa nas IES's localizadas em Mossoró-RN almejando uma formação profissional nas IES's Universidade do Estado do Rio Grande do Norte (UERN), Universidade Federal do Semiárido (UFERSA) e Universidade Potiguar (UNP)².

Realizamos uma pesquisa de campo no período de 2016/2017 de natureza quanti-qualitativa, uma vez que possibilitou a mensuração de uma determinada realidade, ao se debruçar sobre a análise dos dados numéricos, bem como proporcionou a apreensão da individualidade dos sujeitos, em seu contexto integral, almejando analisar o fenômeno sobre a visão das(os) pesquisadas(os) (GODOY, 1995).

Tais sujeitos estão distribuidos nessas instituições, em diversos cursos de graduação, da seguinte forma: 10 na UERN, 10 na UNP e 09 na UFERSA, totalizando 29 (vinte e nove) jovens que moram em Russas-CE, viajam diariamente para Mossoró-RN e que se dispuseram a responder o nosso questionário. A aplicação do questionário buscou traçar o perfil socioeconômico desses estudantes mediante perguntas de múltiplas escolhas. A entrevista semiestrutura possibilitou a apreensão das dificuldades de manter-se nas referidas universidades e prosseguir nos estudos.

Posto isto, após a leitura do artigo, é possivel apontar algumas considerações como os elementos motivadores que impulsionam esta juventude a ir para outro estado e as principais dificuldades inerentes a este processo educacional. Apontamos, também, reflexões acerca da politica de educação superior e a importância da assistência estudantil na garantia do

\footnotetext{
${ }^{2}$ A pesquisa, ora apresentada, foi realizada para compor o trabalho monográfico intitulado: "NINGUÉM TIRA O TRONO DO ESTUDAR": o direito a educação superior e suas limitações, defendida na Faculdade de Serviço Social da Universidade do Estado do Rio Grande do Norte (UERN), sob a supervisão acadêmica da prof. ${ }^{a}$ esp. ${ }^{a}$ Maria Suzana Sousa Leite, no ano de 2017.
} 
direito à educação, bem como para amenizar as desigualdades educacionais entre as classes sociais.

\section{Educação no cenário brasileiro}

O Brasil, em seu processo histórico de desenvolvimento social, cultural e econômico, alicerçou um caráter dual no campo educacional (LIBÂNEO, 2012). A consolidação da academia no país considerou, primordialmente, as demandas do desenvolvimento impulsionado pelas condições econômicas e políticas do século XIX, acirrando as desigualdades existentes entre as classes sociais, os gêneros e as etnias, configurando as universidades brasileiras como meio elitizado e excludente da maior parte da população (FÁVERO, 2006).

Iniciando nossos apontamentos a partir de 1964 (fim da democracia e início da Ditadura Militar), a educação brasileira foi vista sob a ótica de "grande alavancadora do desenvolvimento, sendo utilizada como meio de inculcação da ideologia do governo autoritário” (MOURA, 2007, p. 11), com o intuito de transformar o Brasil em um país desenvolvido. Desse modo, a educação se fundamentará na continuidade dos primórdios de sua história no Brasil, ou seja, dando sequência ao desenvolvimento voltado para formar mão de obra para atender às requisições do mercado de trabalho.

Inerente ao desenvolvimento da política de educação temos a regulamentação da assistência estudantil, pela Constituição de 1967, a partir da obrigação das instituições escolares de dispor serviços que visassem assistir aos necessitados oferecendo condições para continuar seus estudos (SILVEIRA, 2012), no entanto esta assistência não se efetivava na realidade.

Destacamos que a gênese da assistência à(ao) estudante brasileira(o) encontra-se ancorada na expansão do ensino para as classes populares, as quais demandaram condições de permanência no espaço escolar. Este fato levou o Estado a se responsabilizar pela criação de mecanismos que visassem a continuidade dos estudos destes sujeitos. Assim, o Departamento de 
Assistência ao Estudante (DAE) foi criado em 1970 com a finalidade de padronizar a política de assistência estudantil, ou seja, de instituir programas desconsiderando as especificidades de cada região brasileira, sendo uma "politica de assistência ao estudante universitário em nível nacional" (SILVEIRA, 2012, p. 55).

A partir de 1974 se inicia as reivindicações contra a ditadura militar, tanto trabalhadoras(es) como estudantes vão as ruas reivindicando direitos e mudanças politicas. A década de 1980 inicia-se com a efervescência dos movimentos sociais, defendendo eleições diretas para presidente, além de inúmeras outras demandas: estudantes, mulheres, operárias(os), bem como movimentos sociais como o da reforma sanitária que pressionaram os ditadores para a instauração da democracia.

No que tange ao acesso à educação neste período,

\begin{abstract}
De acordo com o Censo de 1980, a população brasileira em idade escolar é de aproximadamente 23 milhões, da qual 7.540 .451 não frequentam a escola de $1^{\circ}$ grau, portanto, $1 / 3$. Na zona rural, a situação ainda é pior. De um total de 9.229.511 pessoas em idade escolar, quase metade não frequenta a escola. $O$ índice de analfabetismo no Brasil é de 25,5\%, portanto, também no terreno da universalização do ensino de $1^{\circ}$ grau, os governos militares não lograram êxito (PALMA FILHO, 2010, p. 123).
\end{abstract}

Este é o panorama educacional o qual a República democrática terá que enfrentar mediante a Constituição da República Federativa do Brasil de 1988, promulgada no primeiro governo eleito por votação direta sob o poder de José Sarney (1985-1990). Esta Constituição apresenta inúmeros avanços no âmbito da garantia dos direitos sociais, consolidando parcialmente as requisições da mobilização popular.

A Carta Magna de 1988, em seu título VIII da ordem social, capítulo III da educação, da cultura e do desporto, destina os artigos 205 ao 214 para o trato específico da educação como sendo direito de todas(os), portanto, dever do Estado assegura-lo com qualidade, igualdade, gratuidade e universalidade. Dentre estes artigos destacamos: 
Art. 206. O ensino será ministrado com base nos seguintes princípios: $\left(\right.$ EC n $^{\circ} 19 / 9$ e EC 53/2006)

I - Igualdade de condições de acesso e permanência na escola;

$[\ldots]$

III - pluralismo de ideias e de concepções pedagógicas, e coexistência de instituições privadas de ensino;

[...]

Art. 209. O ensino é livre à iniciativa privada [...] (BRASIL, 2013, p. 60-61).

Estes elementos embasam a discussão da continuidade da responsabilidade estatal frente a garantia do acesso e da permanência no meio escolar, sendo que deve ser executado de forma igual para todas(os). Outro elemento que enfatizamos é a constitucionalização da iniciativa privada para a oferta de serviços educacionais, ou seja, em meio ao recorrente desmonte das políticas sociais públicas, a possibilidade de privatização da educação é legalizada na Carta Magna vigente. Por vez, o artigo 214 traz a premência da reforma da Lei de Diretrizes e Bases da Educação (LDB) e a constituição de um sistema nacional de educação.

A Lei Federal no 9.394 [1996] [...]estabelece uma efetiva coordenação do Ministério da Educação, criando, desse modo, condições para o desenvolvimento de uma política para o setor da educação em âmbito nacional. Nesse sentido, o artigo $9^{\circ}$ atribui à União a responsabilidade pela elaboração de um Plano Nacional de Educação [...]. Estabelece, ainda, um sistema de colaboração entre Governo Federal, Estados e Municipios. Atribui, também, à União, em colaboração com esses entes federativos, a responsabilidade pela elaboração de diretrizes para a Educação Básica (Educação Infantil, Ensino Fundamental e Ensino Médio), princípios esses que nortearão os currículos e seus conteúdos mínimos, de modo a assegurar formação básica comum (PALMA FILHO, 2010, p. 130).

A LDB, promulgada em 1996, traz as inovações citadas, bem como a importância do financiamento levando a criação do Fundo de Manutenção e Desenvolvimento do Ensino Fundamental e de Valorização do Magistério (FUNDEF), que visa o repasse de recursos entre o Estado e os Municípios em conformidade proporcional ao número de estudantes matriculados no referido ensino (Idem).

Destarte, com o processo de consolidação do neoliberalismo no país, a partir da década de 1990, segundo Libâneo (2012), as políticas educacionais 
brasileiras, adaptadas as requisições dos organismos internacionais, se tornam politicas pobres direcionadas para o atendimento das classes populares.

Com isto, teremos uma "dualidade da escola pública brasileira atual, caracterizada como uma escola do conhecimento para os ricos e como uma escola do acolhimento social para os pobres" (Idem, p. 13), sendo que a população que detém maior poder aquisitivo terá maiores oportunidades de acessar um modelo educacional eficaz, tendo em vista a possibilidade de comprar um serviço que deveria ser ofertado pelo Estado sob a concepção de direito com gratuidade e qualidade. Este dualismo irá rebater no nivel superior de forma a premeditar quais sujeitos terão acesso ao mesmo e que possuirão condições de permanecer nele, reafirmando o caráter elitista das universidades públicas. Discutiremos a seguir sobre este panorama das universidades brasileiras.

\section{Educação superior e as classes populares}

No cenário brasileiro há um distanciamento entre as(os) egressas(os) do ensino médio e as(os) ingressas(os) na educação superior, posto que "entre a decisão de prestar o vestibular e o momento de inscrição há um longo caminho a ser percorrido [...]" (ZAGO, 2006, p. 230). Esta realidade pode ser explicada por dois fatores: a oferta desigual da educação superior e a heterogeneidade da população brasileira, ambos ligados aos processos de formação social, politica, econômica e cultural do Brasil.

O acesso à educação superior passou a ser problematizado a partir do primeiro Plano Nacional de Educação (PNE), com vigência de 2001-2010 (BRASIL, 2001a). Tornando-se questão prioritária na agenda pública da luta pela garantia dos direitos sociais, metas e estratégias foram encadeadas para amenizar a problemática da exclusão social nas universidades brasileiras.

Destarte, o PNE (2001-2010), em sua meta 12, objetivou possibilitar o ingresso de $30 \%$ da população, na faixa etária de 18 a 24 anos, nas IES's. Para concretizar esta meta, o governo federal, articulado com as demais esferas de governo, empenhou-se em sancionar legislações que promovessem a inclusão 
dessas(es) jovens na academia, quais sejam: Lei 10.260 (BRASIL, 2001b): estabelece o Fundo de Financiamento ao Estudante do Ensino Superior (FIES); Lei 11.096 (BRASIL, 2005), dispõe sobre a criação do Programa Universidade para Todos (PROUNI); Decreto 5.800 (BRASIL, 2006), institui o sistema Universidade Aberta do Brasil (UAB); Decreto 6.096 (BRASIL, 2007), cria o Programa de Apoio a Planos de Reestruturação e Expansão das Universidades Federais (REUNI); Decreto 7.234 (BRASIL, 2010), institui o Programa Nacional de Assistência Estudantil (PNAES).

Desse modo, segundo Nierotka e Trevisol (2016, p. 23),

A democratização do acesso à educação superior, particularmente dos jovens de baixa renda, passou a ganhar espaço na agenda dos governos e da sociedade brasileira apenas nos anos recentes, desencadeando políticas públicas de expansão e interiorização das vagas, assim como ações afirmativas voltadas aos grupos sociais mais excluídos.

Estes aportes legais são de respeitável mérito, entretanto não escamoteiam as críticas sobre a sua organicidade. Vejamos: FIES, PROUNI e UAB são iniciativas que tecem crescente mercantilização, precarização e desresponsabilização do Estado frente à garantia da oferta gratuita e de qualidade da educação, conforme preconiza as legislações e pactos internacionais sobre a educação como direito humano.

No que tange ao REUNI e o PNAES são programas que deverão ser articulados às lutas sociais, uma vez que assegurar a sua concretude é um desafio diante a conjuntura política e econômica a qual vivemos e que delineia caminhos para o desmonte das políticas públicas sociais e a privatização das instituições asseguradoras das necessidades básicas, em um sistema diversificado de financiamento (AGAPITO, 2016) como instituído pelo REUNI, por exemplo.

Vale ressaltar que "o acesso à educação superior, sobretudo da população de 18 a 24 anos, vem sendo ampliado no Brasil [...]. A Pesquisa Nacional por Amostra de Domicílios (PNAD) de 2011 registrou que a taxa bruta atingiu o percentual de $27,8 \%$, enquanto a taxa líquida chegou a $14,6 \%$ " (BRASIL, 2014, p. 41). Desse modo, a taxa de jovens da referida faixa etária 
está muito aquém do mínimo estabelecido, que seria 30\%. Logo, este cenário nos leva a constatar que estes programas não foram suficientes para possibilitar a elevação do percentual de ingressantes no ensino superior.

O novo PNE (2014-2024), aprovado pelo Congresso Nacional, estabelece a ampliação da meta 12 do antigo plano, ou seja, "elevar a taxa bruta de matrícula na educação superior para 50\% (cinquenta por cento) e a taxa líquida para 33\% (trinta e três por cento) da população de 18 (dezoito) a 24 (vinte e quatro) anos [...]" (Ibidem). Para tanto, adota estratégias como ampliação das vagas em instituições federais de ensino profissional, científico e tecnológico e no sistema UAB, ampliação das concessões do FIES e PROUNI, bem como a ampliação da assistência estudantil e da inclusão dos sujeitos das classes populares, mediante políticas de ação afirmativa como a Lei $n^{\circ}$ 12.711/2012 (BRASIL, 2014) - Lei de Cotas.

É forçoso chamarmos a atenção para a atual conjuntura econômica e politica a qual estamos inseridas(os), tornando estas iniciativas importantes para o ingresso, a curto prazo, dos sujeitos historicamente marginalizados, porém elas instituem o desmonte da politica pública educacional, acarretando a fragilização, sucateamento e precarização das universidades públicas.

Somado a estes elementos temos a concentração das universidades em cidades de elevado desenvolvimento socioeconômico, o que acarreta implicações para o acesso e permanência de estudantes que residem em localidades longínquas. Neste contexto, Santos (2005, p. 29-30; 38) afirma que os

[...] processos de transformações da sociedade contemporânea [...] definem diferentes expressões da Questão Social. [...] pequenas cidades $[\ldots]$ por não oferecem alternativas de subsistência para os mesmos, favorecem a sua expulsão para cidades de maior porte [...] em busca de uma melhoria de vida. [...] Esses alunos deslocam-se todos os dias de suas cidades [...] através de ônibus ou transporte alternativo escolar, que são pagos pelas prefeituras de suas cidades de origem e, em alguns casos, pelos próprios alunos, acarretando uma série de dificuldades, tanto financeiras como de locomoção, para os mesmos. 
Desse modo, buscou-se pontuar algumas dificuldades relacionadas ao acesso e permanência nas IES brasileiras, retratando a realidade da juventude russana, a qual será estudada a seguir.

\section{Quando o direito é negado, a saída é viajar!}

Para elucidar os vários percalços existentes para ter acesso à educação superior e as dificuldades no interior das universidades brasileiras realizamos uma pesquisa de campo, a qual contou com a participação de estudantes de diversos cursos em três universidades com distintas administração e gerência, sendo uma estadual, uma federal e outra privada. Localizadas na cidade de Mossoró-RN, estas universidades constituem espaços acadêmicos almejados pelas(os) residentes em Russas-CE.

A cidade de Russas-CE faz parte do Vale do Jaguaribe, que é composto por 21 munícipios, sendo destes 06 limítrofes a referida cidade (IPECE, 2007). A cidade que é almejada pelas(os) cearenses, residentes nos munícipios próximos ao estado potiguar, é Mossoró. Realizamos a investigação em três universidades, como supracitado: UERN, UFERSA e UNP que constituem as principais escolhas dos sujeitos envolvidos em nossa pesquisa, como será explicitado a seguir.

\section{Caracterização dos sujeitos}

Nossa pesquisa foi dividida em duas etapas com o propósito de caracterizar os sujeitos inseridos neste contexto social e educacional: na primeira etapa, aplicamos um questionário com perguntas fechadas para 29 estudantes aplicado no ano de 2016; na segunda, foi realizada, no ano de 2017, uma entrevista semiestruturada com 09 estudantes, dos quais responderam o questionário e foram escolhidos aleatoriamente.

Estas(es) estudantes buscam, em sua maioria (90\%), acesso à educação superior diferente daquela que lhe é oferecida em sua região, seja pela afinidade do curso, seja pela limitada oferta de vagas ofertadas ou, ainda, seja pela administração da IES (pública ou privada) e modalidade de ensino (presencial ou a distância). 
Estes sujeitos podem ser caracterizados da seguinte forma: majoritariamente, são mulheres, pessoas sem deficiência, moram com os pais e não possuem filhas(os). Em sua maioria, as(os) estudantes não possuem renda para arcar com as dividas advindas do acesso e permanência nas IES's, tendo em vista que 45\% desse universo depende dos pais para este pagamento. O que diz respeito as despesas, 48\% dos sujeitos se depara com uma conta mensal de $R \$ 250,00$ a $R \$ 300,00$ em contrapartida aos $17 \%$ dos sujeitos que possuem uma despesa de $\mathrm{R} \$ 350,00$ a $\mathrm{R} \$ 400,00$.

Assim, podemos constatar que o gasto mensal é variável em decorrência de elementos como a administração da mantenedora - se ela é estadual, federal ou privada -, o curso e o semestre, considerando que, a depender desses últimos dois aspectos, as despesas podem ser mais elevadas devido os livros, o quantitativo de aulas no contra turno, de xerox, dentre outros fatores.

Um elemento crucial que rebate veemente no pagamento dessas despesas é a renda familiar: o questionário foi aplicado quando o salário equivalia a $\mathrm{R} \$ 880,00$, ou seja, $65 \%$ dos nossos sujeitos contavam com uma renda igual ou superior a $R \$ 1.760,00$, para ser destinados tanto para as contas da faculdade como para as contas da família no geral. Depreende-se que o acesso a um curso de graduação é mediado pelo quesito renda, ou seja, aqueles sujeitos que possuem uma renda familiar consideravelmente razoável possuem maiores chances de ingressar no curso que deseja em outro estado.

É inevitável falarmos dos programas que instauram um desmonte da politica educacional gratuita, de qualidade e universal, em que dos 10 estudantes do ensino superior privado 09 possuíram acesso por intermédio do FIES e do PROUNI. Este fato reafirma o cunho burguês, seletivo e excludente da universidade pública, uma vez que os individuos das classes populares e que estudaram o nível da educação básica em escolas públicas, agora ingressam em IES privada.

As universidades públicas gratuitas e de melhor qualidade, via de regra, que as universidades privadas, são as mais cobiçadas e as que dispõem de cursos mais seletivos aos quais têm maior acesso estudantes brancos, estratos médios e superiores de renda e, 
paradoxalmente, os que frequentaram o ensino elementar e médio no sistema privado (SANCHES, 2014, p. 08).

Outro ponto que abre um leque de discussão é sobre a população negra neste ensino. Dos 29 sujeitos, apenas 01 autodeclarou-se como negro, em contrapartida aos 20 sujeitos que se consideraram como pardos, o que nos faz questionar sobre o que é uma cor parda.

Segundo o Instituto Brasileiro de Geografia e Estatística (IBGE) (1999), são incluídas "[...] nesta categoria a pessoa que se declarou mulata, cabocla, cafuza, mameluca ou mestiça de preto com pessoa de outra cor ou raça [...]". Ou seja, a cor parda é uma forma de amenizar a condição de carregar os traços de negra(o) visando sanar as discriminações e preconceitos construídos socialmente, em consonância com o processo de branqueamento vivenciado pela sociedade brasileira em meados dos anos de 1950 (MUNANGA, 2003).

\section{Percalços da realidade social de universitárias(os) viajantes}

Nesta segunda etapa da pesquisa os sujeitos foram selecionados, aleatoriamente, mediante os questionários. Estes foram designados por pseudônimos, assegurando o sigilo perante a identidade das(os) envolvidas(os) na pesquisa, com o intuito de evitar possíveis danos que possam ser acarretados a partir das informações prestadas.

Suas falas foram transcritas fielmente, segundo gravação de áudio realizada com a permissão de cada um(a), concedida a partir do seu direito de liberdade e oficializada mediante assinatura do Termo de Consentimento Livre Esclarecido (TCLE). É válido frisar que, algumas falas foram transcrevidas, no decorrer deste tópico, com a identificação do pseudônimo atribuído a cada estudante e a instituição de estudo.

Participaram da nossa entrevista 09 estudantes, divididos entre as IES's UERN, UFERSA e UNP, nos turnos matutino e noturno. Destes 05 consideram-se homens e 04 mulheres. Nesta limitação da investigação: 07 sujeitos dividem sua vida universitária com alguma atividade remunerada, em contrapartida a apenas um sujeito que recebe bolsa. 
A condição de estudante-trabalhador(a) é uma realidade que se intensifica nessa conjuntura (SANTOS, 2009), a qual o sujeito busca ter vínculo empregatício para auxiliar o pagamento das despesas com o ingresso na universidade. Esta, por sua vez, pode instituir - como critério para a seleção de bolsas - não participar de atividade remunerada. Assim, estudantes que trabalham para se manter na universidade, não serão selecionados para receber bolsas de assistência estudantil, uma vez que o trabalho será um impedimento para o recebimento destas.

Desse modo, qual explicação é encontrada por essas(es) jovens de Russas-CE para ingressar nas IES's de Mossoró-RN, submetendo-se a viagens diárias?

A localização, a oferta do curso desejado, a condição financeira e a possibilidade de não abrir mão de alguns compromissos - como o trabalho são elementos que levam a juventude russana a se deslocar, diariamente, para a cidade potiguar, negando-se a aceitar a imposição e naturalização de cursar as licenciaturas ofertadas pela Faculdade de Filosofia Dom Aureliano Matos (FAFIDAM), em Limoeiro do Norte - CE, cidade limítrofe a Russas-CE.

É imperioso ressaltar que esta condição não se apresenta apenas na realidade dos sujeitos cearenses: “[...] porque apesar de eu morar hoje no Ceará, mas quando comecei a [...]estudar eu morava em Apodi [RN]... Então a mais próxima que tem, que oferece o meu curso, na época era a UERN, a questão da localização apesar de não ser tão perto, né?” (DANDARA, UERN, 2017).

A questão da proximidade da cidade, onde há a oferta do curso, remete as pioneiras politicas educacionais em que o ensino desenvolvido, após a proclamação da Independência (1889), foi, primordialmente, voltado para a elite e restrito as regiões onde havia intensa desenvoltura econômica e politica, ou seja, a antiga e atual capital brasileira, na época Bahia e Rio de Janeiro, respectivamente (ROCHA, 2010).

Aufere-se que, em seus primórdios, o desenvolvimento educacional, em especial o ensino superior, estava limitado a algumas cidades desenvolvidas econômica e politicamente, acarretando desigualdades de qualidade e de 
avanço das práticas educativas. Posto isto, as IES's "refletem, como espelhos, as desigualdades e a distribuição desigual do poder na sociedade" (NIEROTKA; TREVISOL, 2016, p. 23).

A escolha de qual curso começar envolve a perspectiva de ingresso no mercado de trabalho e a subjetividade, que, por sua vez, não descartará os elementos apontados em linhas anteriores.

[...] o curso de ciência da computação é ... no início eu não... não gostava muito dele não, eu achava que não combinava muito, mas no decorrer que eu fui ... fui cursando eu fui gostando do curso e, eu sou... trabalho como professor, então eu vi como ... a computação sendo como alguma oportunidade de melhorar o ensino. Por isso escolhi esse curso (TARSILA, UFERSA, 2017).

Assim, compreendemos que a escolha do curso vai além do desejo de profissionalização, uma vez que insatisfeito com o estudo não há a possibilidade de desistir, e que este estudo é voltado, majoritariamente, para a visão de tornar-se apta(o) ao emprego.

De acordo com Zago (2006, p. 230), “os estudantes não são todos estudantes no mesmo grau e os estudos ocupam um lugar variável em suas vidas. Tal constatação encontra toda sua expressão quando se analisam a escolha pelo curso e as condições de acesso e de permanência no ensino superior". A ânsia de obter conhecimento, voltado para a possibilidade de empregar a força de trabalho, acarreta inúmeras dificuldades, as quais iremos nos aprofundar a partir deste momento.

Ao perguntarmos como os nossos sujeitos dividem seu tempo para os estudos, a família, o relacionamento afetivo, cuidar de si, para a diversão, obtivemos respostas que podem ser representadas pela fala de Leila (UERN, 2017):

[...] Eu acordo 4:30... 4:20, aí eu venho pra aqui pra UERN, aí eu desço no trabalho... aí eu chego em casa é seis horas da noite. Da viagem que eu chegar, eu vou pras coisas mais importante que é ... fazer...a ... preparar os trabalhos, as atividades, estudar, pra, pro outro dia. Enfim, essas coisas da faculdade são sempre as coisas mais importantes. [...] E família acaba sendo mais no fim de semana, sair, diversão e tal. E cuidar de mim... é uma pergunta um pouco assim 
confusa... porque... eu tenho pouco tempo, assim, acabo, acabo... a prioridade acaba sendo estudar e tal [...].

Na sobrecarga da vida universitária se é acrescida a conciliação do tempo para o trabalho e a vida social, que, conforme Zago (2006, p. 235),

Há uma luta constante entre o que gostariam de fazer e o que é possivel fazer, materializada em uma gama variada de situações: carga horária de trabalho, tempo insuficiente para dar conta das solicitações do curso e outras, de ordem social e cultural, condicionadas pelos baixos recursos financeiros (privar-se de cinema, teatro, espetáculos, eventos científicos, aquisição de livros e revistas etc.).

Assim, a vida social é relegada as margens das prioridades dos sujeitos que, assim como possuem direito a formação profissional, possuem o direito à cultura, ao esporte e ao lazer (BRASIL, 2013), porém não usufruem em decorrência destes e outros fatores.

A locomoção, meio pelo qual se alcança o desejo e a realização do direito de profissionalizar-se, em que o tempo é variável entre uma hora e meia a duas horas de viagem, é uma das causas que promovem esta sobrecarga, bem como as dificuldades que rebatem diretamente neste processo educativo, seja no dispêndio de tempo, que poderia ser aproveitado para estudar mais ou para resolver situações do cotidiano, seja ocasionando cansaço físico e mental, levando a desmotivação e o baixo rendimento na formação pela ausência de saúde física e mental.

A questão da distância é [...]às vezes a gente fica de fora, não... não apenas a permanência, mas de você fazer ... um curso com qualidade. Você perde muita coisa, muito minicurso, às vezes certas disciplinas, por conta da distância e porque os horários dos ônibus são muitos limitados, assim.... entra de sete na faculdade vai de onze [...]. (LEILA, UERN, 2017).

[...] o curso que eu faço ele tem aulas no contra turno, então às vezes eu chego em casa de... meia noite, meia noite e pouco e já tenho que voltar as quatro e pouco da manhã, cinco horas da manhã pra assistir aula no contra turno. (DANDARA, UERN, 2017).

[...] eu acredito que a maior dificuldade enfrentada pelos alunos, é ... principalmente pra quem mora fora é o cansaço físico, o cansaço mental. Não é fácil, né? Não é fácil você tentar conciliar trabalho, família ... e faculdade, e dá conta de tudo (MARIA, UNP, 2017). 
O percurso configura-se como o maior impedimento para se ter uma formação de qualidade, em decorrência dos aspectos apontados por nossas(os) protagonistas, e como a principal causa pela existência das dificuldades, as quais destacamos a impossibilidade de participação nas atividades ofertadas pela IES e, em especial, pelo curso o qual estuda.

Essas atividades fazem parte do escopo das universidades, que, segundo a Constituição Federal de 1988, “[...] obedecerão ao princípio da indissociabilidade entre ensino, pesquisa e extensão" (BRASIL, 2013, Art. 207), constituindo a tríade essencial para uma qualificação satisfatória ao passo que proporciona à(ao) discente a apreensão dos estudos teóricos na realidade a qual vivencia. Trazendo estes aspectos para a particularidade da juventude russana, a participação em pesquisa e extensão torna-se inviável, uma vez que estes sujeitos precisam destinar certo tempo para as viagens e contar com transporte e recursos financeiros para a sua locomoção.

Este fato nos leva a questionar sobre a assistência à(ao) estudante que mora em cidade diferente da universidade a qual estuda. Sabemos que, no processo de redemocratização, a assistência estudantil passa a ser assegurada na Constituição Cidadã, a partir do artigo 206, garantindo a "igualdade de condições para o acesso e permanência na escola" (BRASIL, 2013), no entanto, até que ponto vai essa igualdade de acesso e permanência?

[...] eu procuro fazer o que eu posso dentro [...] das minhas limitações, fazer o que posso, pra estudar, pra pesquisar, de ir além... e poder ... com muito esforço... com muita luta ir vencendo até mesmo os obstáculos que às vezes a gente tem de emprego, de cansaço, de transporte ... pra que a gente possa construir um bom currículo acadêmico e uma boa formação profissional (LEILA, UERN, 2017).

Diante a realidade estudada, a condição financeira se alia a distância para, negativamente, atacar o direito à educação superior que já é negado para esses sujeitos nessa conjuntura: “[...] A maioria dos cursos da UERN, às vezes, o aluno termina o curso todo ... sem fazer um... um estágio, sem se profissionalizar... se faz o estágio, às vezes, também não é remunerado... às vezes o aluno tem que pagar pra estagiar, pra se locomover" (DANDARA, UERN, 2017). 
O estágio curricular é uma atividade assegurada pela LDB, a qual rege que, "o ensino será ministrado com base no principio da vinculação entre a educação escolar, o trabalho e as práticas sociais" (BRASIL, 1996, artigo $1^{\circ}$, parágrafos $2^{\circ}$ e $3^{\circ}$, inciso XI), visando aperfeiçoar a(o) estudante para a prática profissional. Contudo, na atual conjuntura, para que isto ocorra é necessário que a(o) discente arque com as despesas advindas desse processo, ou seja, será necessário que a(o) aluna(o) pague o que é inerente ao ensino superior, que deveria ser público e gratuito.

Posto isto, "uma efetiva democratização da educação requer certamente políticas para a ampliação do acesso e fortalecimento do ensino público, em todos os seus niveis, mas requer também politicas voltadas para a permanência dos estudantes no sistema educacional de ensino" (ZAGO, 2006, p. 228). Logo, a condição de uma instituição ser pública não significa que ela seja gratuita, uma vez que as despesas com xerox, alimentação nas dependências da IES, a locomoção até ela, dentre outros elementos ficam a cargo da(o) estudante que deverá encontrar meios e estratégias para o pagamento dessas despesas.

Conquanto, os obstáculos apresentados em decorrência do trajeto e da condição financeira, algumas vezes, não são vistos como negação de direito, mas são naturalizados, refletindo a incorporação e inculcação das ideias meritocráticas ${ }^{3}:$ “...] quem faz a instituição é o aluno, né? Depende muito do aluno, do ... do aluno querer buscar sempre mais, não só a instituição, mas o aluno ele sempre tem que buscar cada vez mais melhorias, né?” (MARIA, UNP, 2017).

Como reivindicar um direito o qual não se tem consciência que ele existe? Como exigir do Estado a garantia de uma formação profissional de qualidade quando se acredita que deve partir tão somente do esforço pessoal? Esta ausência do conhecimento acerca do direito acontece também em relação

\footnotetext{
3 A este pensamento denominamos de meritocracia: mito fundado, segundo Johnson (1997, p. 146-147) na ideologia de que cada um poderá superar a pobreza se possuir esforço suficiente, chegando assim a uma favorável ascensão social. Considerada como "sistema social [...] a [sua] definição de talento e capacidade é viesada em favor de grupos privilegiados que estabelecem padrões que refletem a si mesmos e seus interesses e meios formativos". Assim, este esforço pessoal ressaltado desconsidera as condições objetivas as quais regem a sociedade e que impõem a cada um/a decisões que nem sempre são condizentes com a sua vontade.
} 
a política de assistência estudantil, em que alguns das(os) entrevistadas(os) desconheciam a existência da mesma e aquelas(es) que conheciam possuíam uma noção vaga sobre a mesma.

Um ponto importantíssimo que não podemos deixar de problematizar é a assistência estudantil na IES privada, que logo nos leva ao questionamento: existe esta política nas dependências de uma instituição particular? Para respondermos este questionamento analisamos o Programa de Apoio ao Estudante (PAE) da UNP. Este programa foi instituido em 2006 para promover o "[...]bem estar do aluno, facilitando a sua ambiência acadêmica e social" (UNP, 2015, p. 03), e dispõe sobre as ações ofertadas pela instituição para a permanência de seu cliente em seu estabelecimento, ou seja, "prestar apoio ao aluno com vistas à sua efetiva integração acadêmica, por meio de programas de ensino, pesquisa e extensão, da prestação de serviços e do desenvolvimento de ações sociais e educacionais" (Idem, p. 09).

Segundo Ramalho (2013, p. 24), a assistência estudantil congrega “a organização de serviços de apoio discente ou iniciativas que busquem democratizar o acesso ao ensino e favorecer a permanência do estudante no contexto escolar". Ou seja, é voltada para as(os) estudantes de baixa renda com a finalidade de amenizar as desigualdades sociais no meio escolar e acadêmico, evitar a evasão e promover o êxito nos estudos, tendo em vista que a carência de condições de permanência é fator crucial para o não acesso à universidade: "porque tem muito aluno [...] que não vai, porque não tem condições de pagar [...]Tipo, o ônibus é caro, merenda é caro, é ... ter que comprar livros é caro, porque os livros não são baratos, então eu acho que a principal dificuldade é essa, né, ter que manter" (QUITÉRIA, UNP, 2017).

Posto isto, se manter na universidade é desafiante quando não há serviços e programas que possam atenuar as dificuldades inerentes a este espaço. Diante deste cenário, é imperioso destacar o redirecionamento dado as bolsas de iniciação científica e de docência: muito embora sejam utilizadas para auxiliar a permanência das(os) estudantes nas universidades, seu objetivo é assegurar que a(o) discente participe das atividades dos projetos de pesquisa e extensão. "Em suma, as concessões dessas bolsas de permanência 
visam estar em harmonia com a politica de assistência estudantil, considerada a especificidade das demandas acadêmicas geradas pela vulnerabilidade social e econômica dos estudantes" (KOWALSKI, 2012, p. 93).

Podemos então, elucidar tal afirmação com a fala de Olga (UERN, 2017): “[...] o que melhorou pra mim até agora foi ter conseguido a bolsa do PIBIC 4 , que aí eu consigo manter, me manter por enquanto pagando o ônibus [...]”. Assim, o recurso de bolsas se constitui como auxílio fundamental para subsidiar a permanência das(os) universitárias(os), intermediando a necessidade financeira e o direito de acesso a graduação para aquelas(es) estudantes da classe trabalhadora, que, cada vez mais, ocupam os bancos escolares das universidades, seja por meio do PROUNI, FIES, ou seja através da politica de cotas sociais e raciais.

Por conseguinte, o recurso financeiro é elemento fundamental para custear as despesas advindas desse processo de formação profissional em instituições, historicamente, frequentadas por filhas(os) da classe média e da elite. Porquanto, a assistência à(ao) estudante ainda é uma política frágil, burocrática e demanda maiores investimentos, uma vez que, segundo Kowalski (2012, p. 103), "nem sempre há uma relação estreita entre o aumento de vagas e o aumento de recursos transferidos pelo MEC para as IES".

Logo, o que deveria ser voltado para a inclusão, torna-se excludente, ao passo que se configura como um setor seletivo e deficiente de financiamento (CISLAGHI; SILVA, 2012), haja vista a "[...] sua marginalização no conjunto das prioridades acadêmicas e administrativas" (FARIA, 1993, p. 208 apud ALVES, 2002, p. 07).

Conquanto, a discussão no âmbito das mutações sociais, dos processos produtivos reprodutivos do capital, a expansão do setor informal, a crescente privatização das políticas sociais públicas asseguradoras dos direitos sociais, o papel do Estado, bem como o compromisso social dos demais entes federados para com tais direitos nos leva a depreender que as desigualdades sociais presentes nos bancos escolares, em particular, no meio universitário,

\footnotetext{
${ }^{4}$ Programa de Iniciação Científica.

Interfaces da Educ., Paranaíba, v.10, n.28, p. 189 à 213, 2019 ISSN 2177-7691
} 
possui estreita vinculação com a organicidade do sistema econômico. À Vista disso, "[...]o caráter explícito desta subordinação [das práticas educativas aos interesses do capital] é uma clara diferenciação da educação ou formação humana para as classes dirigentes e a classe trabalhadora" (CAMPOS; MELLO, 2011, 05).

Esta diferenciação da educação é explícita quando analisamos o contexto o qual se encontra as(os) estudantes da classe trabalhadora, no qual "o ensino superior representa para esses estudantes um investimento para ampliar suas chances no mercado de trabalho cada vez mais competitivo [...]Essa observação suscita uma reflexão sobre o que normalmente chamamos 'escolha'. Quem, de fato, escolhe?" (ZAGO, 2006, p. 231).

$\mathrm{O}$ referido sistema que impõe a profissionalização como requisito para que haja a venda da força de trabalho é o mesmo que nega e naturaliza as condições de negligência do direito à educação superior, fortalecendo o seu caráter de elite, enquanto consolida um ensino técnico para o rápido ingresso no mercado de trabalho das classes populares, uma vez que a prioridade é tornar o indivíduo apto ao trabalho em contrapartida a formação profissional para a realização pessoal.

Assim, em meio aos rebatimentos do sistema capitalista na garantia dos direitos, consideramos pertinente questionarmos sobre o que pode ser feito para atenuar tais dificuldades deste processo de formação realizado em outro estado. A resposta foi unânime: a necessária participação do município no financiamento da locomoção. Não só a ajuda de custo aparece como resposta para tais desafios, mas configura-se como primordial, temos também as políticas de assistência estudantil para este grupo de estudantes que não moram na mesma cidade onde se localiza as IES's frequentadas: um investimento maior para possibilitar um número crescente de bolsas; a construção de uma casa de apoio para acolher esses sujeitos quando houver atividades no contra turno, possibilitando economizar dinheiro no pagamento de passagens além da mensalidade; o estágio remunerado e bolsa trabalho aparecem como sendo alternativas para subsidiar às(aos) universitárias(os) 
que seguem os estudos procurando estratégias que deveriam ser tomadas pelo Estado.

\section{Reflexões finais}

A discussão sobre o espaço universitário brasileiro e a sua ocupação pela juventude das classes populares nos leva, inevitavelmente, a retroceder na história da educação no Brasil, uma vez que é no trajeto de consolidação e desenvolvimento do sistema educacional que encontramos a âncora dos reflexos atuais: universidades públicas majoritariamente frequentadas por jovens de classe média e empresas educacionais privadas ocupadas pelos advindos da classe trabalhadora.

O que se considera democratização e expansão da educação superior não passa de iniciativas que perpetuam o quadro desigual de acesso e permanência nas universidades públicas. Ora, a democratização em tela rebate veemente nos princípios fundamentais do direito à educação: universidade, qualidade e gratuidade.

Em contrapartida, temos a suma importância da política de assistência estudantil como direito que tutela o direito à educação, sendo assim imprescindivel a formulação de políticas que considerem a particularidade das(os) estudantes de baixo poder aquisitivo, bem como daquelas(es) que não residem na cidade da IES a qual estuda.

Considerar a assistência estudantil como a salvadora da Pátria é, no mínimo, ingenuidade. Acreditamos em sua significativa contribuição, no entanto, não devemos nos ater somente a ela. Como nossas(os) protagonistas afirmaram é preciso que o município possua responsabilidade para com elas(es), é necessário que ele arque ou compartilhe do financiamento da locomoção diária.

A partir disso, apontamos as seguintes dificuldades apresentadas a juventude universitária advinda de Russas-CE: a distância, a qual impossibilita a participação nas atividades ofertadas pelo curso e pela universidade, bem como afeta no rendimento escolar uma vez que acarreta desgaste físico e mental em decorrência das viagens diárias. O custo financeiro 
de manter-se na IES se constitui, também, um desafio tanto para estudantes como para o Estado na formulação de uma política de assistência estudantil que ofereça suporte para a categoria estudantil.

Vale ressaltar que, para a juventude russana além da dificuldade de permanecer no ensino superior há, também, a dificuldade de chegar até este ensino, tendo em vista as condições de locomoção, bem como o financiamento do transporte para a realização da mesma. Estas dificuldades são camufladas pela força motriz e pelo desejo do possivel ingresso no mercado de trabalho, ou seja, é a conquista de um diploma em prol da possibilidade de vender a força de trabalho visando a satisfação das necessidades de subsistência.

Salientamos que, apesar da crítica voltada para a graduação atender às demandas do modo de produção capitalista, reconhecemos que esta é uma necessidade concreta da classe trabalhadora, que depende do aprimoramento dos seus conhecimentos para buscar um emprego que lhe permita manter uma condição de vida mais ou menos satisfatória.

Diante do exposto, deixamos registrada nossas reflexões finais da seguinte maneira: é necessário unirmos nossas forças contra a onda neoliberal e capitalista que se constitui uma afronta aos nossos direitos; é pertinente exigirmos do Estado a sua primazia pelas politicas sociais públicas; é preciso termos o sentimento de coletividade, de uma classe que sofre, dia e noite, com o retrocesso dos direitos sociais, dentre eles, a educação. Nossa libertação deve ser almejada a partir de um processo de aprendizagem crítica e emancipadora, sem as amarras do capital, visando a transformação da sociedade atual.

\section{Referências bibliográficas}

AGAPITO, A. P. F. Ensino Superior no Brasil: expansão e mercantilização na contemporaneidade. Temporalis, Brasília, ano 16, n. 32, 2016. Disponível: <http:/ / periodicos.ufes.br/temporalis/article/view/14064>. Acesso em: 15 dez. 2016.

ALVES, J. M. A assistência estudantil no âmbito da política de Ensino Superior Pública. Serviço Social em Revista, Londrina, v. 5, n. 1, 2002. Disponivel em: <http://www.ssrevista.uel.br>. Acesso em: 20 dez. 2016. 
BRASIL. Constituição da República Federativa do Brasil de 1988. Brasília: Gráfica Senado, 2013.

. Decreto $\mathrm{n}^{\circ}$ 5.800, de 8 de junho de 2006. Dispõe sobre o Sistema Universidade Aberta do Brasil - UAB. Brasília, 2006.

Decreto $n^{\circ}$ 6.096, de 24 de abril de 2007. Institui o Programa de Apoio a Planos de Reestruturação e Expansão das Universidades Federais - REUNI. Brasília, 2007.

. Decreto $\mathrm{n}^{\circ} 7.234$, de 19 de julho de 2010. Dispõe sobre o Programa Nacional de Assistência Estudantil - PNAES. Brasília, 2010.

. Lei 9. 394, de 20 de dezembro de 1996. Estabelece as Diretrizes e Bases da Educação Nacional. Brasília, 1996.

. Lei $\mathrm{n}^{\circ}$ 10. 172, de 09 de janeiro de 2001. Aprova o Plano Nacional de Educação e dá outras providências. Brasília, 2001a.

. Lei $\mathrm{n}^{\circ}$ 10.260, de 12 de julho de 2001. Dispõe sobre o Fundo de Financiamento ao estudante do Ensino Superior e dá outras providências. Brasília, 2001b.

- Lei $\mathrm{n}^{\circ}$ 11.096, de 13 de janeiro de 2005. Institui o Programa Universidade para Todos - PROUNI, regula a atuação de entidades beneficentes de assistência social no ensino superior; altera a Lei no 10.891, de 9 de julho de 2004, e dá outras providências. Brasília, 2005.

. Ministério da Educação. Secretaria de Articulação com os Sistemas de Ensino. Planejando a Próxima Década: Conhecendo as 20 Metas do Plano Nacional de Educação. Brasília: Ministério da Educação. Secretaria de Articulação com os Sistemas de Ensino (MEC/SASE), 2014.

CAMPOS, D. A. de; MELLO, M. A. Inclusão: acesso e permanência no Ensino Superior brasileiro. Dossiê Políticas Educativas. Porto Alegre, v. 5, n. 1, p. 1531, 2011.

CISLAGHI, J. F.; SILVA, M. T. da. O Plano Nacional de Assistência Estudantil e o Reuni: ampliação de vagas versus garantia de permanência. SER Social, Brasília, v. 14, n. 31, 2012.

DANDARA. Entrevista concedida a Luciene Araújo. Russas, 16 fev. 2017.

DRUMMOND, J. G. de F. Educação Superior. In: CASTRO, C. L. F. de; GONTIJO, C. R. B. A.; A. E. de N. (Org's). Dicionário de políticas públicas. Barbacena: EdUEMG, 2012. P. 152- 154. 
FÁVERO, M. de L. de A. A universidade no Brasil: das origens à Reforma Universitária de 1968. Educar, Curitiba, n. 28, 2006. Disponivel: <http://revistas.ufpr.br/educar/article/download/7609/5423>. Acesso em: 20 ago. 2016.

GODOY, A. S. Introdução à pesquisa qualitativa e suas possibilidades. Revista de Administração de Empresas. São Paulo, v. 35, n. 2, p. 57-63, 1995.

IBGE. INSTITUTO BRASILEIRO DE GEOGRAFIA E ESTATÍSTICA. Pesquisa nacional por amostra de domicílios (PNAD). [Brasília], 1999. Disponível em: <www.ibge.gov.br/home/estatistica/populacao/trabalhoerendimento/pnad9 9/metodologia99.shtm>. Acesso 14 abr. 2017.

IPECE. INSTITUTO DE PESQUISA E ESTRATÉGIA ECONÔMICA DO CEARÁ. Ceará em mapas: Informações georreferenciadas e espacializadas para os 184 municipios cearenses. Fortaleza, 2007. Disponivel em: <http://www2.ipece.ce.gov.br/atlas/>. Acesso em: 28 abr. 2018.

JOHNSON, A. G. Dicionário de Sociologia: Guia prático da linguagem. Rio de Janeiro: Jorge Zahar Ed., 1997. P. 146 e 147.

KOWALSKI, A. V. Os (des)caminhos da politica de Assistência Estudantil e o desafio na garantia de direitos. Tese (Doutorado em Serviço Social). 2012. 180 f. Pontificia Universidade Católica do Rio Grande do Sul. Faculdade de Serviço Social. Programa de pós-graduação em Serviço Social. Porto Alegre.

LEILA. Entrevista concedida a Luciene Araújo. Russas, 17 fev. 2017.

LIBÂNEO, J. C. O dualismo perverso da escola pública brasileira: escola do conhecimento para os ricos, escola do acolhimento social para os pobres. Revista Educação e Pesquisa. São Paulo, v. 38, n. 1, p. 13-28, 2012.

MARIA. Entrevista concedida a Luciene Araújo. Russas, 21 fev. 2017.

MOURA, D. H. Educação básica e educação profissional e tecnológica: dualidade histórica e perspectivas de integração. Revista Holos, Ano 23, Vol. 2, 2007, p. $04-30$.

MUNANGA, K. Algumas Considerações sobre a Diversidade e a Identidade Negra no Brasil. RAMOS, M. N.; ADÃO, J. M.; BARROS, G. M. N. (Coord.). Diversidade na educação: reflexões e experiências. Brasília: Secretaria de Educação Média e Tecnológica, p. 35-50, 2003.

NIEROTKA, R. L.; TREVISOL, J. V. Os jovens das camadas populares na universidade pública: acesso e permanência. Revista Katálysis, Florianópolis, v. 19, n. 1, p. 22-32, jan./jun. 2016. Disponivel em: < www.scielo.br/scielo.php?pid=S1414- 
49802016000100022\&script=sci_abstract\&tlng=pt>. Acesso em: 28 nov. 2017.

OLGA. Entrevista concedida a Luciene Araújo. Russas, 17 fev. 2017.

PALMA FILHO, J. C. A República e a Educação no Brasil: Primeira República (1889-1930). UNESP. UNIVERSIDADE ESTADUAL PAULISTA. Caderno de formação: formação de professores educação, cultura e desenvolvimento. Pró reitoria de graduação. Universidade Virtual do Estado de São Paulo. São Paulo: Cultura Acadêmica, 2010, p. 71-84.

QUITÉRIA. Entrevista concedida a Luciene Araújo. Russas, 22 fev. 2017.

RAMALHO, L. E. G. Abordagem avaliativa da politica de Assistência Estudantil em uma instituição de ensino profissional. 2013. 164 f. Dissertação (Mestrado Profissional em gestão e avaliação da educação pública). Universidade Federal de Juiz de Fora. Programa de pós-graduação profissional em gestão e avaliação da educação pública. Juiz de Fora.

SANCHES, R. R. As Politicas de Assistência Estudantil no Brasil. A Revista História, Movimento e Reflexão. v. 2, n. 1, 2014 Disponivel: <www.revistadigital.unibarretos.net/index.php/historia/article/view/28>.

Acesso 30 Nov. 2016.

SANTOS, J. K. P. dos. Quem somos? Um estudo sobre o perfil socioeconômico dos estudantes do curso de Serviço Social da UERN. 2005. Monografia (Graduação em Serviço Social). Universidade do Estado do Rio Grande do Norte. Faculdade de Serviço Social. Mossoró.

SANTOS, L. S. A juventude de origem popular em busca do ensino superior público: ente sonhos, dificuldades e desigualdades. Scientia Plena, Sergipe, v. 05, n. 11, nov., 2009.

SILVEIRA, M. M. da. A Assistência Estudantil no Ensino Superior: uma análise sobre as políticas de permanência das universidades federais brasileiras. 2012. 137 f. Dissertação (Mestrado em Politica Social) - Centro de Ciências Jurídicas, Econômicas e Sociais, Universidade Católica de Pelotas, Pelotas.

TARSILA. Entrevista concedida a Luciene Araújo. Russas, 21 fev. 2017.

UNP. UNIVERSIDADE POTIGUAR. Programa de Apoio ao Estudante (PAE) da Universidade Potiguar. 2. ed. Natal: Edunp, 2015.

ZAGO, N. Do acesso à permanência no ensino superior: percursos de estudantes universitários de camadas populares. Revista Brasileira de Educação, Curitiba, v. 11, n. 32, maio/ago, pp. 226-370, 2006. 